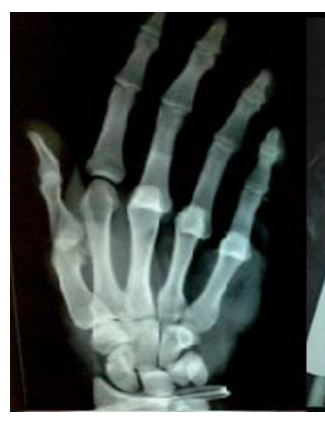

ISSN: $2395-1958$

IJOS 2017; 3(1): 564-567

(C) 2017 IJOS

www.orthopaper.com

Received: 21-11-2016

Accepted: 22-12-2016

Efstathios Drampalos

(A) Department of Orthopaedics,

Wythenshawe hospital, UK

(B) Department of Orthopaedics, Asklipieion Voulas hospital,

Athens, Greece

\section{Lazaros Oikonomidis}

Department of Orthopaedics, Manchester Royal Infirmary, UK

\section{Jeremy Oakley}

Department of Orthopaedics,

Wythenshawe hospital, UK

\section{Ioannis Michos}

Department of Orthopaedics, Manchester Royal Infirmary, UK

Efstathios Chronopoulos Univerity department of Orthopaedic Agia Olga hospital, Athens, Greece

\section{Correspondence}

Efstathios Drampalos

(A) Department of Orthopaedics, Wythenshawe hospital, UK

(B) Department of Orthopaedics, Asklipieion Voulas hospital,

Athens, Greece

\section{International Journal of} Orthopaedics Sciences

\section{Vitamin D status and bone turnover marker levels in Greek women with fragility hip fracture}

\author{
Efstathios Drampalos, Lazaros Oikonomidis, Jeremy Oakley, Ioannis \\ Michos and Efstathios Chronopoulos
}

DOI: $\underline{\text { http://dx.doi.org/10.22271/ortho.2017.v3.i1i.81 }}$

\section{Abstract}

There is little data regarding Vitamin D deficiency in Greece. Also conflicting are the data regarding the bone turnover during the acute hip fracture interval and the situation is even more complex considering the recently developed bone turnover markers (BTMs). The aim of this study was to evaluate the parameters of bone mineral homeostasis of women with fragility hip fracture using the recently developed BTMs of carboxy-terminal collagen crosslinks (CTx) and the procollagen type 1 aminoterminal propeptide (PINP) and to determinate vitamin D (25-OHD) levels of elderly Greek women with acute hip fracture. 38 self-sufficient, community-living Greek women with acute hip fracture were included. A similar number of age- and sex-matched controls with no clinically evident fractures were included in the study meeting the same inclusion and exclusion criteria. To exclude the effect of trauma blood samples were drawn within 24 hours from the fracture. Hip fracture group had significantly lower serum 25-OHD levels and significantly higher intact parathormone $(\mathrm{PTH})$ levels compared to the control group but no correlation between PTH and 25-OHD was found in both groups. CTx was significantly correlated with PINP in the total group and in both groups separately but there was no statistical difference of their levels between the two groups. There was high prevalence of severe Vitamin D deficiency within the postmenopausal Greek women with acute hip fracture and the fracture did not influence the above mentioned BTMs. The processes of bone resorption and bone production are in balance during the first 24 hours after the fracture.

Keywords: Hip fracture; bone turnover markers; CTX; PINP; vitamin D

\section{Introduction}

Fragility fractures of the hip are common among women with osteoporosis and contribute to an increase of morbidity and mortality in the elderly. Subclinical vitamin D deficiency is related to decreased bone strength and it is also a risk factor for osteoporotic hip fractures ${ }^{[1-3]}$. Inadequate sun exposure and poor nutrition in elderly people may cause vitamin D insufficiency ${ }^{[4,5]}$. Several studies from Europe, Australia and Asia have revealed presence of variable vitamin D deficiency and secondary rise in parathormone (PTH) levels in women with hip fracture ${ }^{[6-10]}$. The prevalence of vitamin D deficiency though, is not well known in hip fracture patients from Greece.

Controversy persists whether osteoporotic fractures can be prevented with vitamin D supplementation ${ }^{[11,12]}$. Furthermore, there is little and conflicting data regarding the bone turnover during the acute hip fracture interval and the situation is even more complex considering the recently developed bone turnover markers (BTMs), which are that is the carboxy-terminal collagen crosslinks (CTx) and the pro-collagen type 1 amino-terminal propeptide (PINP) ${ }^{[13-14]}$. Therefore, this matched control study was carried out to evaluate the parameters of bone mineral homeostasis including levels of serum 25-hydroxyvitamin D (25OHD) and intact PTH in Greek postmenopausal women with acute hip fracture.

\section{Material and Methods}

Thirty-eight women with low energy hip fractures from the women admitted to our institution because of an acute hip fracture were included with the following inclusion criteria: selfsufficiency (independency), community-living. 
Women with fracture following a road traffic accident and with tumor, primary hyperparathyroidism or secondary causes of osteoporosis (i.e. renal insufficiency, corticosteroid use) were excluded. Participants on treatment with calcium and vitamin $\mathrm{D}$, anti-osteoporotic or other medications potentially influencing the bone metabolism were also excluded from the study. None of the patients had alcohol consumption of 3 or more units/day or smoked more than 10 cigarettes/day

Control individuals were selected from women after the age of 65 referred to our outpatients department for a routine checkup for osteoporosis. From these women referred to our outpatients department 43 age-matched to the fracture group with no clinically evident osteoporotic fractures were included in the study meeting the same inclusion and exclusion criteria. All patients were informed of the nature of the study, and consent was obtained from each participant.

Blood samples were collected within 24 hours of admission. Fasting venous samples of all study subjects were drawn between 8 and 11 a.m. within $24 \mathrm{~h}$ from the time of the fracture to rule out the effect of the trauma or immobilization on 25-OHD levels and BBMs ${ }^{[15]}$. Serum was separated in a centrifuge and stored at $-20^{\circ} \mathrm{C}$ for $25-\mathrm{OHD}, \mathrm{CTx}$ and PINP assays. Plasma was used for to measure the intact PTH. All tests were conducted under the supervision of a qualified biochemist.

Serum calcium and serum phosphate were determined with standard methods on the day of collection. Blood urea, creatinine, bilirubin, aspartate aminotransferase, and alanine aminotransferase levels were also determined to assess liver and renal function and exclude secondary causes of osteoporosis (i.e. renal insufficiency). The normal levels of serum calcium and phosphate were $8.7-10.2$ and 2.5-4.5 $\mathrm{mg} / \mathrm{dl}$ respectively. PINP was assayed as a bone formation marker (total procollagen type 1 amino-terminal propeptide kit, Roche Diagnostics Mannheim, Germany; reference values for post-menopausal women: $16-73 \mathrm{ng} / \mathrm{ml})$. CTx was assayed as a bone resorption marker ( $\beta$-CrossLaps/serum kit, ECLIA Roche Diagnostics Mannheim, Germany; reference values for post-menopausal women: $<1.008 \mathrm{ng} / \mathrm{ml}$ ). Plasma Parathyroid hormone (PTH) was measured by an enzyme-labeled immunometric assay, which detects intact PTH molecules (IMMULITE 2000 intact PTH immunoassay, Loss Angeles, U.S.A.; reference values: $16-87 \mathrm{pg} / \mathrm{ml}$ ). Serum vitamin D was determined by measuring serum 25-OHD (Vitamin D total immunoassay, Roche Diagnostics Mannheim, Germany). Diagnosis of vitamin D deficiency was considered when levels of $25-\mathrm{OHD}$ were $<20 \mathrm{ng} / \mathrm{ml}^{[16]}$.

Analysis was performed using computer software SPSS for Windows, version 14.0 (SPSS Inc., Chicago, IL, USA). Difference between the two means was performed using Student's t-test. Correlations were examined using Pearson's correlation test. Chi-square test was used to assess differences in the proportion between qualitative data. The confidence intervals for the correlation of the mean values were $95 \%$ and level of statistical significance was set at $p<0.05$.

\section{Results}

The summary statistics of the study subjects is given in table 1 . There was no significant difference in age between the hip fracture and the control group $(p=0.601)$. Hip fracture group had significantly lower serum 25-OHD levels $(p<0.001)$, significantly higher intact PTH levels $(p<0.001)$ and significantly lower phosphate $(\mathrm{P})$ levels $(p<0.001)$ compared to the control group. None of the women had biochemical parameters suggestive of primary hyperparathyroidism.
Compared to the $83 \%$ of the participants with hip fracture with serum 25-OHD levels less than $20 \mathrm{ng} / \mathrm{ml}$, only $33 \%$ of the control group had 25-OHD less than $20 \mathrm{ng} / \mathrm{ml}$. This difference is also statistically significant $(p<0.001)$.

Correlations were also examined within the two groups. Among the hip fracture participants (table 2), there is positive correlation between CTx and PINP ( $\mathrm{r}=0.612, p<0.001)$. The same is observed between CTx and PINP in the control group (table 3, r=0.654, $p<0.01$ ). Also, CTX and PINP are significantly correlated in the total group $(\mathrm{r}=0,555, p=0,01)$.

In hip fracture participants with 25-OHD deficiency $(<20$ $\mathrm{ng} / \mathrm{ml}$ ), the positive correlation between CTx and PINP is even more significant $(r=0.796, p<0.001)$. Also for the non-fracture group although there is significant correlation between $\mathrm{Ca}$ and PINP we don't think this is of clinical value (table 3 ).

Table 1: Baseline characteristics of the women with hip fracture and controls.

\begin{tabular}{|c|c|c|c|}
\hline Parameters & $\begin{array}{c}\text { Fracture } \\
(\mathbf{n = 3 8 )}\end{array}$ & $\begin{array}{c}\text { Control } \\
(\mathbf{n = 4 3 )}\end{array}$ & $\mathbf{p}$ Value \\
\hline Mean age (years) & $81.2 \pm 10.3$ & $79.9 \pm 11.4$ & $p=0.601$ \\
\hline 25-OHD (ng/ml) & $14.8 \pm 9,6$ & $26 \pm 11$ & $p<0.001$ \\
\hline intact PTH (pg/ml) & $118.8 \pm 69.9$ & $81.4 \pm 40.7$ & $p<0.001$ \\
\hline P (mg/dl) & $3.5 \pm 0,5$ & $3.9 \pm 0.3$ & $p<0.001$ \\
\hline CTx (ng/ml) & $0.40 \pm 0.21$ & $0.34 \pm 0.17$ & $p=0.149$ \\
\hline PINP (ng/ml) & $68.5 \pm 122$ & $45.3 \pm 29.9$ & $p=0.247$ \\
\hline Ca (mg/dl) & $8.6 \pm 0.44$ & $8.8 \pm 0.33$ & $p=0.094$ \\
\hline Vitamin D deficiency, n (\%) & $31(83)$ & $13(33)$ & $p<0.001$ \\
\hline Secondary & $24(66)$ & $19(48)$ & $P=0.052$ \\
Hyperparathyroidism, n (\%) & 24 & \\
\hline
\end{tabular}

Table 2: Correlation matrix for Ca, P, VITD, PTH, CTx and PINP (fracture group)

\begin{tabular}{|c|c|c|c|c|c|c|}
\hline Variables & Ca & P & VITD & PTH & CTx & PINP \\
\hline Ca & & -0.182 & -0.269 & -0.015 & 0.004 & -0.032 \\
\hline P & & & 0.076 & 0.028 & -0.017 & -0.094 \\
\hline VITD & & & & 0.140 & -0.233 & -0.208 \\
\hline PTH & & & & & 0.184 & 0.199 \\
\hline CTx & & & & & & $0.612 * *$ \\
\hline
\end{tabular}

**. Correlation is significant at the 0.01 level.

*. Correlation is significant at the 0.05 level.

Table 3: Correlation matrix for Ca, P, VITD, PTH, CTx and PINP (non fracture group)

\begin{tabular}{|c|c|c|c|c|c|c|}
\hline Variables & Ca & P & VITD & PTH & CTx & PINP \\
\hline Ca & & $-0,026$ & 0,177 & 0,183 & 0,003 & $0,314^{*}$ \\
\hline P & & & $-0,262$ & 0,08 & $-0,057$ & 0,132 \\
\hline VITD & & & & $-0,041$ & 0,141 & $-0,062$ \\
\hline PTH & & & & & $-0,2$ & 0,02 \\
\hline CTx & & & & & & $0,654^{* *}$ \\
\hline
\end{tabular}

*. Correlation is significant at the 0.05 level.

\section{Discussion and Conclusion}

The present study evaluates the parameters of bone mineral homeostasis in postmenopausal women with fragility hip fracture. According to the results 25-OHD was significantly lower and intact PTH was significantly higher in the hip fracture group compared to controls, consistent with previously reported results $[7,17,18]$. There are several studies reporting high prevalence of vitamin D deficiency in hip fracture women around the world. In a study on a British population (Baker et al.), from 98 women with neck of femur fracture, $40 \%$ had $25-\mathrm{OHD}$ level of $<10 \mathrm{ng} / \mathrm{ml}$, and mean serum $25-\mathrm{OHD}$ of $13.8 \mathrm{ng} / \mathrm{ml}$. Similarly in another study from the US, $50 \%$ of women with osteoporotic hip fracture had a serum 25-OHD level less than $12 \mathrm{ng} / \mathrm{ml}^{[18]}$. The same vitamin 
D deficiency is reported in a study from Italy as $21.6 \%$ of patients with hip fracture had serum 25-OHD less than 20 $\mathrm{ng} / \mathrm{ml}{ }^{[17]}$. In Spain, $67 \%$ of the patients with hip fracture had vitamin D levels less than $20 \mathrm{ng} / \mathrm{ml}$, and $55 \%$ had elevated intact $\mathrm{PTH}{ }^{[9]}$.

Our results show that $83 \%$ of the hip fracture participants had a serum 25-OHD less than $20 \mathrm{ng} / \mathrm{ml}$ and $51 \%$ had a level of less than $10 \mathrm{ng} / \mathrm{ml}$; these percentages were higher compared to the aforementioned studies. On the control group only $33 \%$ had a serum 25-OHD less than $20 \mathrm{ng} / \mathrm{ml}$ and $2.56 \%$ less than $10 \mathrm{ng} / \mathrm{ml}$. These high percentages of vitamin D deficiency involve women from the Mediterranean country of Greece. As far as we are aware this is the first report in literature of high prevalence of Vitamin D deficiency in Greek women with fragility hip fracture. The cause for such a high prevalence of vitamin D deficiency in our study might be multifactorial and needs further investigation. According to other studies, inadequate dietary calcium and vitamin $\mathrm{D}$ intake, inadequate sun exposure, environmental pollution and lack of food fortification with vitamin $\mathrm{D}$ might contribute to hypovitaminosis $\mathrm{D}[9,10,17,18]$. Infact, the present study was conducted in the capital city of Athens with known problems of environmental pollution and with a common life style of limited sun exposure particularly for elderly people. Furthermore, it is our assumption that the economic crisis has negatively influenced diet and vitamin $\mathrm{D}$ intake as also life style and sun exposure.

Osteomalacia has been confirmed and levels of $\mathrm{P}$ are within or lower than normal limits in patients with hip fracture ${ }^{[20,21,22]}$. In our study $81 \%$ of the hip fracture women had evidence of biochemical osteomalacia comparing to the $30 \%$ of the control group. This may also explain the lower levels of mean serum $\mathrm{P}$ in the patients with hip fracture although within normal range. Regarding the relationship between intact PTH and 25-OHD, although intact PTH is significantly higher in the fracture group (table 1), no correlation between PTH and 25-OHD was found in both groups. According to the literature when the 25OHD level become insufficient, the intact PTH level generally rises ${ }^{[20]}$. Twenty six (59\%) of the 44 women in the current study with a low 25-OHD had an elevated PTH level ( $>87$ $\mathrm{pg} / \mathrm{ml}$ ). According to Chapuy et al. low serum 25-OHD does not always lead to an increase in serum PTH ${ }^{[20]}$. Furthermore, Sahota et al ${ }^{[23]}$. suggested that a slight decrease in serum calcium and a substantial reduction in 25-OHD may partly cause failure of the parathyroid gland to provide with an adequate PTH response. It may well be that the cutoff for definition of an elevated PTH level requires further examination but on the other side this would mean a dramatic rise in the diagnosis, and possible mis-diagnosis, of secondary hyperparathyroidism.

Concerning the role of the new BBMs, CTx and PINP, in bone fragility it has been suggested that hip-fracture patients have decreased bone production and increased bone resorption when compared to age-matched controls ${ }^{[13,24,25,26,27]}$. In most of these studies measurements have been performed after the incident. In our study bone resorption and production markers were found positively correlated in both groups $(p<0.001)$ implying coupling between the two processes. This relation was even stronger in patients with $25-\mathrm{OHD}$ less than $10 \mathrm{ng} / \mathrm{ml}$ $(p<0.001)$. In addition, no significant difference between the fracture and the control group was found for the BTMs ( $p=0.149$ for CTx and $p=0.247$ for PINP). This result is very likely to indicate that the fracture did not have any influence on their levels and bone production is positively related to bone resorption during the immediate post fracture period also.
As a conclusion, Vitamin D tends to be low and PTH increased in Greek postmenopausal women with fragility fractures. This has been previously demonstrated (though not specifically reported for Greek patients). Also, in contrast with previous studies patients with hip fracture have balanced bone metabolism and this finding is reported for the first time in literature as far as we are aware. Replication of the results with larger, prospective studies using the recently developed BTMs would be of value.

\section{Ethics Committee Approval}

Ethics committee approval was received for this study from Asklipieion Athens General Hospital Ethics Committee.

\section{Informed Consent}

All patients were informed of the nature of the study, and consent was obtained from each participant.

\section{References}

1. Grisso J, Kesley JL, Strom BL et al. Risk factors for hip fracture in black women: The Northeast Hip Fracture Study Group. N Engl J Med. 1994; 33:1555-1559.

2. Ooms ME, Vlasman P, Lips P et al. The incidence of hip fractures in independent and institutionalized elderly people. Osteop Int. 1994; 4:6-10.

3. Tinetti A, Baker D, McAvay G et al. A multifactorial intervention to reduce the risk of falling among elderly people living in the community. N Engl J Med. 1994; 331:821-827.

4. Gloth FM, Gundberg CM, Hollis BW et al. Vitamin D deficiency in homebound elderly persons. JAMA. 1995; 274:1683-1686.

5. Goldray D, Mizrahi-Sasson E, Merdler C et al. Vitamin D deficiency in elderly patients in a general hospital. J Am Geriatr Soc. 1989; 37:589-592.

6. Malavolta N, Pratelli L, Frigato M, Mule R, Mascia ML, Gnudi S. The relationship of vitamin D status to bone mineral density in an Italian population of postmenopausal women. Osteoporos Int. 2005; 16:16911697.

7. Sakuma M, Endo N, Oinuma T, Hayami T, Endo E, Yazawa $\mathrm{T}$ et al. Vitamin $\mathrm{D}$ and intact $\mathrm{PTH}$ status in patients with hip fracture. Osteoporos Int. 2006; 17:16081614.

8. Nurmi I, Kaukonen JP, Lüthje P et al. Half of the patients with an acute hip fracture suffer from hypovitaminosis D: a prospective study in southeastern Finland. Osteoporos Int, 2005; 16:2018-2024.

9. Larrosa M, Gomez A, Casado E, Moreno M, Vázquez I, Orellana C et al. Hypovitaminosis D as a risk factor of hip fracture severity. Osteoporos Int. 2012; 23:607-614. [Epub 2011 Mar 11].

10. Dhanwal DK, Sahoo S, Gautam VK, Saha R. Hip fracture patients in India have vitamin D deficiency and secondary hyperparathyroidism Osteoporos Int. 2013; 24:553-557.

11. Bischoff-Ferrari HA, Willett WC, Wong JB, Giovannucci E, Dietrich T et al. Fracture prevention with vitamin D supplementation: a meta-analysis of randomized controlled trials. JAMA. 2005; 293:2257-2264.

12. Porthouse J, Cockayne S, King C, Saxon L, Steele E, Aspray $\mathrm{T}$ et al. Randomised controlled trial of calcium and supplementation with cholecalciferol (vitamin D3) for prevention of fractures in primary care. BMJ. 2005; 330:1003-1006.

13. Akesson K, Vergnaud P, Gineyts E, Delmas PD, Obrant 
KJ. Impairment of bone turnover in elderly women with hip fracture Calcif Tissue Int. 1993; 53:162-169.

14. Erem C, Tanakol R, Alagol F, Omer B, Cetin O. Relationship of bone turnover parameters, endogenous hormones and vitamin D deficiency to hip fracture in elderly postmenopausal women Int J Clin Pract. 2002; 56:333-337.

15. Thiebaud D, Burckardt $\mathrm{P}$, Costanza $\mathrm{M}$ et al. Importance of albumin, 25(OH)-vitamin D and IGFBP-3 as risk factors in elderly women and men with hip fracture Osteoporos Int. 1997; 7:457-462.

16. Holick MF. Vitamin D deficiency N Engl J Med. 2007; 357:266-81

17. Nuti R, Martini G, Valenti R, Gambera D, Gennari L, Salvadori $\mathrm{S}$ et al. Vitamin D status and bone turnover in women with acute hip fracture. Clin Orthop Relat Res. 2004; 422:208-213.

18. LeBoff MS, Kohlmeier L, Hurwitz S, Franklin J, Wright J, Glowacki J. Occult vitamin D deficiency in postmenopausal US women with acute hip fracture. JAMA 1999; 281(16):1505-1511.

19. Baker MR, McDonnel H, Peacock M, Nordin BE. Plasma 25-hydroxy vitamin $\mathrm{D}$ concentrations in patients with fractures of the femoral neck. Br Med J. 1979; 1(6163):589.

20. Chapuy MC, Preziosi P, Maamer M, Arnaud S, Galan P, Hercberg S et al. Prevalence of vitamin D insufficiency in an adult normal population. Osteoporos Int. 1997; 7(5):439-443. DOI 10.1007/s001980050030.

21. Hordon LD, Peacock M. Osteomalacia and osteoporosis in femoral neck fracture. Bone Miner. 1990; 11:247-259.

22. Jenkins DH, Roberts JG, Webster D, Williams EO. Osteomalacia in elderly patients with fracture of the femoral neck. A clinico-pathological study. J Bone Joint Surg Br. 1973; 55(3):575-580.

23. Sahota O, Gaynor K, Harwood RH, Hosking D. Hypovitaminosis D and 'functional hypoparathyroidism' the NoNoF (Nottingham Neck of Femur) study. Age Ageing. 2001; 30:467-472

24. Garnero P, Hausherr E, Chapuy MC, Marcelli C, Grandjean H, Muller C et al. Markers of bone resorption predict hip fracture in elderly women: The EPIDOS prospective study. J Bone Miner Res. 1996; 11(10):1531-8.

25. Takahashi M, Kushida K, Hoshino H, Ohishi T, Inoue T. Evaluation of bone turnover in postmenopause, vertebral fracture, and hip fracture using biochemical markers for bone formation and resorption J Endocrinol Invest. 1997; 20(3):112-7.

26. Åkesson K, Vergnaud P, Gineyts E, Delmas PD, Obrant KJ. Impairment of bone turnover in elderly women with hip fracture. Calc Tissue Int. 1993; 53(3):162-169.

27. Cheung CK, Panesar NS, Lau E, Woo J, Swaminathan R. Increased bone resorption and decreased bone formation in Chinese patients with hip fracture. Calc Tissue Int. 1995; 56(5):347-349. 